\title{
Nonsense-mediated mRNA decay at the crossroads of many cellular pathways
}

\author{
Fabrice Lejeune $e^{1,2,3, *}$ \\ ${ }^{1}$ University Lille, UMR8161 - M3T - Mechanisms of Tumorigenesis and Target Therapies, ${ }^{2}$ CNRS, UMR 8161, ${ }^{3}$ Institut Pasteur de Lille, \\ F-59000 Lille, France
}

\begin{abstract}
Nonsense-mediated mRNA decay (NMD) is a surveillance mechanism ensuring the fast decay of mRNAs harboring a premature termination codon (PTC). As a quality control mechanism, NMD distinguishes PTCs from normal termination codons in order to degrade PTC-carrying mRNAs only. For this, NMD is connected to various other cell processes which regulate or activate it under specific cell conditions or in response to mutations, mis-regulations, stresses, or particular cell programs. These cell processes and their connections with NMD are the focus of this review, which aims both to illustrate the complexity of the NMD mechanism and its regulation and to highlight the cellular consequences of NMD inhibition. [BMB Reports 2017; 50(4): 175-185]
\end{abstract}

\section{INTRODUCTION}

Nonsense-mediated mRNA decay (NMD) is a surveillance or quality control mechanism which targets for accelerated decay mRNAs harboring a premature termination codon (PTC) (1-7). In mammals, NMD is activated on an mRNA when the first stop codon of the open reading frame is located more than 50-55 nucleotides upstream of an exon-exon junction (8). Recent studies have shown that NMD can also be elicited when the distance between the first stop codon of the open reading frame and the poly $(\mathrm{A})$ binding protein becomes abnormally long (9-12). From these two NMD activation models has emerged a combinatory model taking both originally proposed activation pathways into account, but this model requires further experimental support $(6,11,13)$.

The proteins UPF1, UPF2, and UPF3X (also called UPF3b) play a central role in NMD and are universally conserved within the eukaryotic kingdom (14). Extensive studies on UPF1

*Corresponding author. Tel: +33-320871059; Fax: +33-320871111; E-mail: fabrice.lejeune@inserm.fr

https://doi.org/10.5483/BMBRep.2017.50.4.015

Received 19 January 2017

Keywords: Cellular pathway, Nonsense mutations, Nonsense-mediated mRNA decay (NMD), Quality control mechanism, UPF proteins have demonstrated that this phosphorylated protein is an RNA helicase that clears the region downstream from a PTC to prepare the mRNA for decay (15-20). Phosphorylation and subsequent dephosphorylation of UPF1 are required to elicit NMD. In addition to their role in NMD, UPF proteins are involved in other cellular mechanisms (see below). Since NMD can be mechanistically different according to the species (14), this review focuses mainly on NMD in human cells and on interactions between the NMD mechanism or NMD factors and other processes occurring in human cells. In particular, we discuss the connections between NMD and upstream or downstream processes involved in gene expression and the influence of various cell pathways on NMD.

\section{NMD ACTIVATION MODELS}

\section{The EJC-dependent activation model}

Experimental data show that a stop codon is recognized as a PTC only if it is located more than 50-55 nucleotides upstream of an exon-exon junction (Fig. 1A) (21-23). A protein complex called EJC (for Exon Junction Complex) is deposited 20-24 nucleotides upstream of exon-exon junctions after pre-mRNA splicing occurs $(24,25)$. EJC recruits NMD factors UPF3X/ UPF $3 b$ and then UPF2. During the pioneer round of translation when the $5^{\prime}$-cap is still bound by the CBP80/CBP20 heterodimer and the poly $(\mathrm{A})$ tail is bound by the poly $(\mathrm{A})$ binding proteins $\mathrm{N} 1$ and $\mathrm{C} 1$ (PABPN1 and PABPC1, respectively), the first ribosome reads the mRNA and removes all EJCs present on its path (26). If the mRNA carries no stop codon more than 50-55 nucleotides upstream of an exon-exon junction, no EJCs will remain on the mRNA once the ribosome reaches the normal stop codon after the pioneer round of translation. The mRNP will then be remodeled to undergo steady-state translation with replacement of CBP80/CBP20 by elF4E and the presence of PABPC1 only on the poly(A) tail. If the mRNA carries a stop codon located more than 50-55 nucleotides upstream of an exon-exon junction, the ribosome will pause at this stop codon. At least one EJC will still be present on the mRNA when the ribosome reaches this stop codon. This EJC then recruits the SURF complex formed by SMG1, SMG8, SMG9, UPF1, and the release factors 1 and 3 (16). SMG1 phosphorylates UPF1, causing the departure of the 


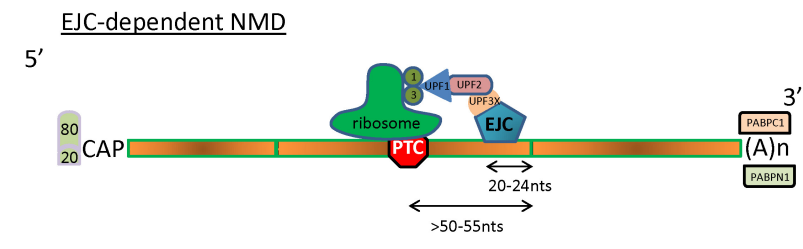

$\underline{\text { PTC-PABPC1 distance-dependent NMD }}$

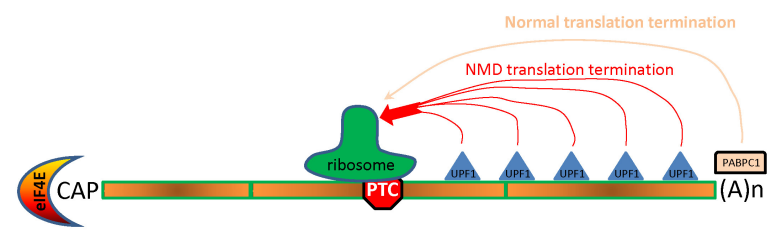

Fig. 1. Models of NMD activation. (A) The EJC-dependent model. PTCs are recognized if they are present more than 50-55 nucleotides upstream of an exon-exon junction during the pioneer round of translation. The mRNA carries the CBP20/CBP80 heterodimer at the $5^{\prime}$ cap and PABPN1 and PABPC1 on the poly(A) tail at the $3^{\prime}$ end. In this model UPF1 is recruited by the UPF3X and UPF2 proteins bound to the exon junction complex (EJC). Translation termination occurs because UPF1 interacts with the release factors eRF1 (1) and eRF3 (3). (B) The PTC-PABPC1 distance model. PTC recognition is based on the probability that translation termination will occur via the interaction between UPF1 and release factors (NMD translation termination) or via the interaction between PABPC1 and release factors (normal translation termination).

ribosome and the release factors (20). Then SMG5, SMG6, SMG7, and the protein phosphatase 2A (PP2A) are recruited, causing the exit of SMG1, SMG8, and SMG9. Phosphorylated UPF1 then interacts directly with the RNA, and its RNA helicase activity is activated so as to remove proteins from the region downstream from the PTC on the mRNA and to prepare the mRNA for decay (15). The RNA helicase MOV10 also seems to be involved in the removing of RNA secondary structures and proteins downstream of PTCs (27). Phosphorylated UPF1 also interacts with the proline-rich nuclear receptor coregulatory protein 2 (PNRC2) to recruit the decapping enzyme DCP1a, involved in the $5^{\prime}$ to $3^{\prime}$ decay pathway (28). Then PP2A dephosphorylates UPF1, and the mRNA decay pathways are activated to degrade the mRNA, from both ends and also via endonucleolytic cleavage by SMG6 in the vicinity of the PTC (29-32).

In this model, NMD occurs only during the pioneer round of translation. This round is characterized by a dedicated translation initiation complex and the presence of the heterodimer CBP80/CBP20 on the $5^{\prime}$ cap, of EJCs on the mRNA, and of PABPC1 and PABPN1 on the poly(A) tail (27, 33, 34). According to the model, only newly synthesized mRNAs are targeted for NMD, and if they are not recognized as NMD targets during the pioneer round of translation, they will be immune to $\operatorname{NMD}(27,35)$.

The EJC-dependent model fits most cases, but some experimental data challenge this model. For instance, EJCs are not present upstream of all exon-exon junctions $(36,37)$. Furthermore, some PTCs located less than 50 nucleotides upstream of the last exon-exon junction trigger $\operatorname{NMD}(38,39)$, and some PTCs located more than 55 nucleotides upstream of the last exon-exon junction do not $(40,41)$.

\section{PTC-PABPC1 distance-dependent activation}

The second model describing activation of NMD in mammalian cells is based on the distance between the PTC and the PABPC1. This model is similar to the model of NMD activation in other species such as yeast, worm, and fly (14). Basically, when the $3^{\prime}$ UTR of an mRNA is abnormally long because of the presence of a PTC for instance, NMD is activated to degrade that specific mRNA (42). In the abovementioned species, the size of the 3'UTR tends to be relatively homogenous, which facilitates recognition of abnormally long 3'UTRs (43). In mammals, the molecular mechanism may be more complex because of evolution, and particularly because of the highly variable size of the $3^{\prime} \cup T R$, from 21 nucleotides to more than $8 \mathrm{~kb}(44)$.

Many reports indicate that the distance between PABPC1 and the PTC is what triggers $\operatorname{NMD}(9-12,45)$. This model suggests that certain cis- or trans-acting elements can provide a measure of the length of the $3^{\prime}$ UTR. In particular, it is thought that specific elements might be involved in regulating NMD on mRNAs with long $3^{\prime} U T R s$ and in preventing unnecessary degradation by NMD. Among these regulatory elements, secondary structures in the 3'UTR might bring PABPC1 closer to the normal stop codon and thus prevent inappropriate activation of NMD under specific conditions (10). Long human 3'UTRs have also been reported to contain NMD-inhibiting regulatory sequences (46).

In the PTC-PABPC1 distance model, NMD occurs during all cycles of translation in an EJC-independent way $(47,48)$. UPF1 has been shown to interact directly with RNA and to concentrate in the $3^{\prime}$ UTR (49-52). UPF1 and PABPC1 thus compete to terminate the translation by interacting with release factor 3 when the ribosome reaches a stop codon that will trigger NMD (in the case of UPF1) or the normal translation termination (in the case of PABPC1) (Fig. 1B). The closer the PTC to the start of the open reading frame, the greater the chances that UPF1 will be involved in terminating translation and eliciting NMD. This model thus suggests a gradient of NMD efficiency, decreasing with increasing proximity of the PTC to the physiological stop codon (38).

\section{The combinatory model}

Given the strong experimental evidence supporting each of these two models, it is difficult to ignore one of them. A combinatory model has been proposed to reconcile the two 
visions, taking both proposed pathways of NMD activation into account $(6,8,13)$. In this model, a PTC can be recognized at two successive steps. During the pioneer round of translation, the EJC-dependent NMD activation pathway would be responsible for recognition of PTC-containing mRNAs as described above. Later, as a fraction of the PTC-containing mRNAs can escape NMD (for example, by being protected from translation for a while), the PTC-PABPC1 distance pathway would take charge of these PTC-containing mRNAs during later rounds of translation. Although such a model can explain the vast majority of cases of NMD activation, some exceptions have already been described that do not fit with this model, indicating that NMD activation remains incompletely understood (53-55).

\section{NMD AND SPLICING}

In mammals, splicing has been implicated in NMD since the discovery that at least one intron must be present downstream of a PTC on the pre-mRNA in order to elicit NMD on the corresponding mRNA $(23,56,57)$. These are the studies that gave rise to the "rule of the 50-55 nucleotides" (41), stating that a PTC elicits NMD only if an exon-exon junction is present more than 50-55 nucleotides downstream of the PTC (58). The molecular explanation came with the identification of a protein complex deposited 20-24 nucleotides upstream of exon-exon junctions as a consequence of splicing $(24,25)$. This complex, called EJC for Exon Junction Complex, is formed by splicing factors (RNPS1, SRm160, UAP56, SAP18, Acinus, Pnn/DRS, and Pinin), exporting factors (UAP56, REF/Aly, TAP/p15, Y14, or Magoh), and a group of four proteins forming the core of the EJC (Y14, Magoh, elF4AIII, and MLN51) (59-71). This complex is fully exported to the cytoplasm before undergoing the pioneer round of translation responsible for PTC detection, in keeping with the cytoplasmic cellular location of NMD $(45,71)$.

While splicing is required for NMD, NMD is also very useful in eliminating defective or unwanted mRNA products generated by splicing. Splicing is indeed the major source of PTC-containing mRNAs, since one-third of the mRNAs generated by alternative splicing are targeted for NMD because of the presence of a PTC $(72,73)$. As more than $95 \%$ of multi-exon pre-mRNAs are subject to alternative splicing (74), NMD needs to be very efficient to eliminate all the unwanted splicing products. Alternative splicing and NMD are involved in regulating many genes under specific cellular conditions. For example, splicing factors such as members of the SR family (75) decrease their own synthesis, when their level is too high, by incorporating into their mRNAs, via alternative splicing, a poison cassette exon harboring an NMD-eliciting PTC $(76,77)$.

\section{NMD AND miRNA}

MicroRNAs (miRNAs) regulate gene expression by either inducing the decay or inhibiting the translation of their target mRNAs. NMD and the miRNA pathway interact at two different levels at least. Firstly, miR128 is reported to regulate the expression of both the UPF1 gene and the MLN51 gene, encoding one of the core components of the EJC (78). This finding suggests fine regulation of NMD efficiency by the miRNA pathway, although the specific conditions under which miR128 targets UPF1 and/or MLN51 mRNAs remain to be elucidated. Secondly, a factor playing a role in both the NMD and miRNA decay pathways has been identified. mRNA decay via the miRNA pathway involves proteins, such as Argonaute, found also in the siRNA pathway. This makes Argonaute a key player of two RNA decay pathways. The protein Argonaute 2 is also reported to inhibit the pioneer round of translation by competing with the heterodimer CBP80/CBP20 for binding to the $5^{\prime}$ cap $(79,80)$. Since CBP80 plays a role in NMD by promoting the interaction between UPF1 and UPF2 during the pioneer round of translation, binding of Argonaute 2 to the $5^{\prime}$ cap promotes NMD inhibition (79-81). It is worth noting that this competition between CBP80/20 and Argonaute 2 occurs only on mRNAs carrying a binding site for miRNA in the $3^{\prime}$ UTR. This limits the number of mRNAs subject to this regulation.

\section{NMD AND STAUFEN-MEDIATED mRNA DECAY (SMD)}

Staufen 1 and Staufen 2 are RNA-binding proteins targeting for accelerated decay mRNAs containing a specific type of hairpin or a double-stranded structure made of complementary Alu elements in the $3^{\prime}$ UTR. Staufen proteins can recruit UPF1 to the mRNA independently of other UPF proteins or EJC components. Once UPF1 is recruited, mRNA decay is triggered by a machinery that has not been yet identified (29). SMD and NMD share a central protein, UPF1, and thus compete for the available UPF1. An example of this competition concerns the proteins myogenin, required for myogenesis, and PAX3, a transcription factor that inhibits the differentiation of myoblasts to myotubes (82). Myogenin mRNA is a natural NMD target and PAX3 mRNA is an SMD substrate. UPF1 can interact either with UPF2, to induce $\mathrm{NMD}$, or with Staufen proteins, to trigger SMD. If the UPF1-UPF2 interaction is favored, NMD will be active, myogenin mRNA will be degraded, and myogenesis will be inhibited. If the UPF1-Staufen protein interaction is favored, SMD will be active, PAX3 mRNA will be degraded, and this will lead to the differentiation of myoblasts to myotubes (83).

NMD factors have been implicated in many different mechanisms that could be antagonistically linked to NMD according to the same principle of factor availability as described above. For instance, as UPF1 has been shown to play a role in maintaining telomere length, in S-phase 
progression, and in histone mRNA decay $(84,85)$. All these processes could be antagonistically related to NMD.

\section{NMD AND TRANSLATION}

NMD and translation are tightly interconnected at different levels. First, PTC recognition requires the translation machinery. Interference with translation by chemicals, suppressor tRNAs, or secondary structures blocking ribosome progression has been shown to impair NMD $(86,87)$. In particular, the translation inhibitors cycloheximide, puromycine, and emetin are reported to strongly inhibit NMD $(87,88)$. Second, NMD affects mRNAs being translated during both the pioneer round and other rounds of translation $(26,47,48)$. During the pioneer round, a peptide is synthesized (89), consistently with the presence of CBP80-bound mRNAs in the subpolysomal fractions of a polysome gradient (33), but this peptide is targeted for rapid decay via stimulation of the proteasome by UPF1 $(90,91)$. Third, several translation initiation factors are required for NMD, such as elF4G (34), elF2 $\alpha$ (33), elF4F (47), and elF3e $(92,93)$. Interestingly, these factors are tightly regulated. An example is elF2 $\alpha$, whose phosphorylated isoform is inactive. Its phosphorylation is induced by various cell stresses, such as hypoxia, endoplasmic reticulum stress due to accumulation of unfolded proteins, and amino acid starvation leading to inhibition of the pioneer round of translation and hence to NMD $(33,94,95)$. Fourth, NMD activation, or more precisely UPF1 phosphorylation, leads to inhibition of translation, so as to prevent initiation of new translation cycles and the synthesis of truncated proteins (96). Finally, the NMD factors UPF1, UPF2, UPF3/UPF3a, and UPF3X/UPF3b have been shown to stimulate translation when tethered to an unspliced mRNA $(97,98)$. Although its molecular mechanism remains unclear, this translation stimulation illustrates the close interconnection of NMD and translation.

\section{NMD AND READTHROUGH}

Readthrough is a natural process leading to incorporation of an amino acid into the growing peptide when the ribosome reaches a stop codon during translation $(6,99)$. So far, readthrough has been found to regulate the expression of four genes in human cells (100). Molecules such as aminoglycosides, ataluren/PTC124, and readthrough compounds (RTC) induce readthrough of PTCs but not of physiological stop codons (99, 101, 102). The involvement of UPF proteins in this mechanism is controversial. Knockout of UPF proteins in yeast was first found to increase readthrough, and this was attributed to decreased translation termination fidelity $(103,104)$. Then it was proposed that readthrough efficiency is independent of the presence or absence of UPF proteins (105). In human cells, knockdown of UPF proteins has recently been reported to impair readthrough. This suggests a role of these proteins in readthrough in humans and hence a link between NMD and readthrough (106).

Favoring PTC readthrough is a highly promising therapeutic approach for genetic diseases caused by a nonsense mutation (107). Yet the readthrough efficiency generated even in the presence of readthrough activator molecules remains low, likely because PTC-readthrough substrates are first NMD substrates, so that the amount of PTC-containing mRNAs available for readthrough is very low. It has therefore been proposed to combine NMD inhibitors with readthrough activators, to improve the synthesis of full-length readthrough proteins. Such combinations have been shown to increase substantially the production of the readthrough proteins from PTC-containing mRNAs in both cell cultures $(108,109)$ and in vivo, in a mouse model (110). Yet the fact that UPF proteins are required for both PTC readthrough and NMD suggests that strategies for inhibiting NMD should exclude targeting any UPF protein, as this would compromise the efficiency of readthrough. The role of UPF proteins in readthrough should be studied in depth in order to propose an efficient therapeutic approach to treating nonsense-mutation-related diseases.

\section{NMD AND THE CYTOSKELETON}

In mammalian cells, NMD has been clearly demonstrated to be a cytoplasmic event (45) occurring during or soon after mRNA export to the cytoplasm (111). Furthermore, NMD factors and substrates have been reported to transit through cytoplasmic foci called P-bodies $(112,113)$. P-bodies are foci scattered through the cytoplasm and containing RNA-degrading enzymes and RNAs such as miRNAs and PTC-containing mRNAs $(114,115)$. As PTC-containing mRNAs are exported to the cytoplasm and transit through P-bodies before being degraded, this suggests that they are transported from the nucleus to P-bodies at least. It has recently been reported that to promote this transport and allow NMD, an active cytoskeleton is required (106). Interestingly, when the cytoskeleton is impaired and in particular when the microtubules are disrupted, NMD factors and substrates are found concentrated in P-bodies, suggesting that the cytoskeleton is responsible either for transporting to P-bodies a factor required for NMD or for transporting PTC-containing mRNPs from P-bodies to the cellular location of NMD (106).

\section{NMD AND APOPTOSIS}

When cells undergo apoptosis, a specific gene expression profile is activated so as to induce cell death. This profile includes both the transcription of specific genes and the decay of targeted proteins. Investigators have wondered whether a quality control mechanism such as NMD is still active during apoptosis or whether it becomes useless, since the accumulation of nonfunctional or deleterious truncated proteins could even be part of the cell death process. This question was recently answered in two studies where the efficiency of NMD was 
measured after activation of apoptosis with chemicals (116, 117). Both studies demonstrated that NMD is inhibited during apoptosis. The molecular mechanism was also determined: UPF1 and UPF2 are targeted and inactivated by caspases 3 and 7. In addition, the UPF fragments generated by caspase cleavage show apoptotic activity, inducing an amplification loop that precipitates cell death (116). This amplification loop is also generated upon NMD inhibition, via expression of apoptotic genes which are normally repressed by NMD: genes encoding cell cycle inhibitors and the caspase activators GADD45 $\alpha$, GADD45 $\beta$, and CDKN1A (117).

The findings of both studies show that an RNA surveillance mechanism such as NMD can be regulated according to the cell status and is a direct target during programmed cell death by apoptosis.

\section{NMD AND AUTOPHAGY}

NMD is a quality control mechanism and a gene regulation pathway for about $5-10 \%$ of human genes (118). When NMD is impaired, many mRNAs are up-regulated and can be translated. The mRNA encoding ATF4 is a natural substrate of NMD which becomes up-regulated when NMD is inhibited. ATF4 is a transcription factor activating the transcription of genes involved in autophagy, a process through which both proteins and organelles are degraded (119). Inhibition of NMD by means of an siRNA against UPF1 or UPF2 causes activation of ATF4 expression, promoting increased autophagy in the cell in response to the synthesis of aberrant proteins. Conversely, activation of NMD by overexpression of UPF1, for instance, leads to minimal autophagy in the cell (120). The ultimate consequence of autophagy is cell death. Autophagy is thus an additional programmed cell death pathway related to NMD inhibition $(116,117)$, alongside apoptosis.

\section{NMD AND THE UNFOLDED PROTEIN RESPONSE}

About $30 \%$ of proteins present in a cell are secreted or transmembrane proteins. They are thus synthesized and folded in the endoplasmic reticulum (ER). When unfolded or misfolded proteins accumulate in the ER, a protein degradation pathway, called the unfolded protein response (UPR), is activated to eliminate them. This response involves activation of certain transcription factors and inhibition of translation, which stops the synthesis of unfolded or misfolded proteins. Another consequence of UPR activation is inhibition of NMD (121). $\mathrm{NMD}$, as a process regulating the expression of some genes, influences the expression of several genes involved in UPR, such as ATF3, ATF4, ATF6, and IRE $\alpha$. Inhibition of NMD thus creates a positive feedback loop (122-124). Interestingly, inhibition of NMD as a first event does not induce UPR. This indicates that the origin of this regulation loop must be ER stress, and not NMD inhibition unrelated to ER stress (122).

The ER could also modulate the efficiency of NMD in another way. The ER is a calcium storage site that can regulate the cytoplasmic concentration of calcium (125). Recently, an increase in the intracellular calcium concentration was found to inhibit NMD (126). This opens prospects for a new therapeutic approach to inhibiting NMD in some cases of nonsense-mutation-related genetic diseases.

\section{NMD IN CELL DIFFERENTIATION AND ORGANISM DEVELOPMENT}

As described above, many genes involved in splicing or NMD (among others) use NMD to regulate their own expression. This suggests that no NMD at all would probably promote chaos in the cell. Accordingly, knockout of UPF1, UPF2, or SMG1 in mouse leads to embryo death very early during development (127-129). This suggests a major role of NMD during development and particularly in the expression of genes involved in the early development and differentiation program. In support of the view that NMD plays a key role in development and in the homeostasis of multi-cellular organisms, only a few patients with a default in the NMD machinery have been reported. Some cases of mental retardation have been attributed to loss of UPF2, UPF3, UPF3X, SMG6, or of an EJC component such as elF4A3 or RNPS1 (130-136).

In mice where UPF2 was conditionally knocked out, some cell populations, such as proliferative cells, were found to be more sensitive than others to a lack of NMD (137). In hematopoietic cells, genomic DNA rearrangements at particular loci generate specific isoforms of immunoglobulins or $\mathrm{T}$ cell receptor (TCR). These DNA rearrangements attest the wide diversity of peptides involved in antigen recognition. Yet two-thirds of these DNA rearrangements result in a faulty message with a PTC and are silenced thanks to NMD (138). When NMD is deficient, aberrant shortened peptides are synthesized from the PTC-containing TCR or immunoglobulin mRNAs and interfere with the lymphocyte maturation process, causing developmental arrest and death of the organism. This highlights the crucial roles played by NMD (139).

\section{NMD AS AN ANTIVIRAL BARRIER}

Besides its interconnection with endogenous cell processes, NMD can also interact with exogenous machineries. For instance, viruses have genomes with an unconventional gene organization as compared to eukaryotic genomes. Splicing and multiple open reading frames encoded by a single mRNA are common in viruses, suggesting that in eukaryotic cells, some virus mRNAs could be targeted by NMD because of the presence of "PTCs". In keeping with this view, downregulation of NMD factors results in a strong increase in the production of viral proteins (140). Viruses have developed strategies for escaping NMD and using components of the NMD machinery to their own advantage. HIV-1, for instance, uses UPF1 and other NMD factors to facilitate the export of its 
RNA molecules from the nucleus thanks to a Rev-UPF1 interaction that prevents UPF2 from binding UPF1 (141). Once in the cytoplasm, UPF1 remains bound to the viral RNA and can also be encapsidated in virions (142). Down-regulation of UPF1 reduces the infectivity of HIV virions, suggesting an unexpected role of UPF1 in promoting infectivity. This could provide a basis for an interesting antiviral approach.

\section{DISCUSSION}

NMD has been found in all eukaryotic organisms studied to date. The role of this quality control mechanism is to eliminate faulty mRNAs harboring a PTC in order to prevent the synthesis of aberrant truncated proteins $(1,2,8)$. In eukaryotes, NMD is also a regulatory pathway for some wild-type genes: $5-10 \%$ of human genes, for instance $(118,143)$. NMD occurs in the cytoplasm, during or after mRNA export to this compartment and before steady-state translation (144). Some proteins involved in NMD, however, are loaded onto the mRNA in the nucleus $(63,71,145)$. To accurately perform its role, NMD must be activated at the right moment, at the right place, and on the right mRNA. All these parameters can be influenced by cell conditions or stimuli, and various other signaling and metabolic pathways are involved. Exactly how many and which mechanisms affect NMD activation is still under investigation, and the list presented here is far from exhaustive. We would like to apologize to colleagues whose work is not cited in this review because of space limitation. As described here, many different mechanisms are also tightly

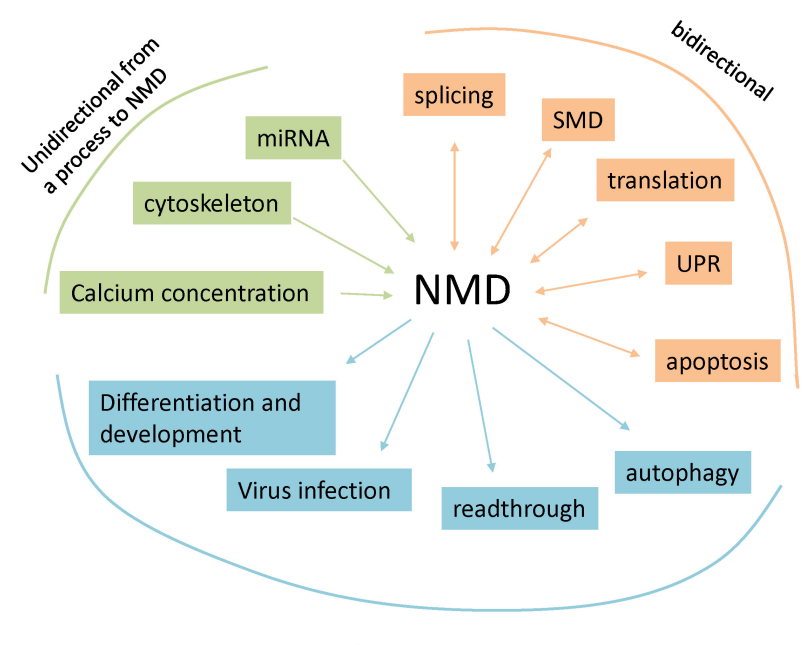

Unidirectional from NMD to the process

Fig. 2. NMD interacts with cellular processes in different ways: (i) bidirectional interactions in which NMD and a cellular process influence each other (bidirectional arrows); (ii) unidirectional interactions in which NMD influences a cellular process (arrows pointing a cellular process); (iii) unidirectional interactions in which a cellular process regulates NMD efficiency (arrows pointing NMD). linked to NMD, such as the miRNA gene regulation pathway, the unfolded protein response, and apoptosis. The interaction of all these pathways with NMD reflects the central role of NMD in cell homeostasis and in the development of multicellular organisms. We can divide the interactions between these processes and NMD into three categories: (i) bidirectional interactions in which NMD regulates a mechanism and this mechanism can also influence NMD efficiency; (ii) unidirectional interactions in which NMD influences a specific process; (iii) unidirectional interactions in which a process influences NMD (Fig. 2). It is crucial to study and understand these interactions, especially because inhibiting NMD appears as an attractive therapeutic approach to correcting nonsense mutations in genetic diseases $(6,146)$. Such therapies will have to allow some NMD to occur or they will have to target their NMD-inhibiting action to specific nonsense-mutationcontaining mRNAs rather than to all PTC-containing mRNAs.

\section{ACKNOWLEDGEMENTS}

F.L. is an Inserm researcher financially supported by the Association Française contre les Myopathies, Vaincre la mucoviscidose, Canceropole Nord-Ouest, and the CNRS.

\section{CONFLICTS OF INTEREST}

The author has no conflicts of interest.

\section{REFERENCES}

1. Karousis ED, Nasif $S$ and Mühlemann $O$ (2016) Nonsense- mediated mRNA decay: novel mechanistic insights and biological impact. Wiley Interdiscip Rev RNA 7, 661- 682

2. Hug N, Longman D and Cáceres JF (2016) Mechanism and regulation of the nonsense-mediated decay pathway. Nucleic Acids Res 44, 1483-1495

3. He F and Jacobson A (2015) Nonsense-Mediated mRNA Decay: Degradation of Defective Transcripts Is Only Part of the Story. Annu Rev Genet 49, 339-366

4. Popp MW and Maquat LE (2014) The dharma of nonsense-mediated mRNA decay in mammalian cells. Mol Cells 37, 1-8

5. Fatscher T, Boehm V and Gehring NH (2015) Mechanism, factors, and physiological role of nonsense-mediated mRNA decay. Cell Mol Life Sci 72, 4523-4544

6. Lejeune F, Benhabiles $H$ and Jia J (2016) Nonsense mutation correction in human diseases: an approach for targeted medicine. Elsevier ed Publisher: Catherine Van Der Laan 1-192

7. Hwang J and Kim YK (2013) When a ribosome encounters a premature termination codon. BMB Rep 46, 9-16

8. Kurosaki T and Maquat LE (2016) Nonsense-mediated mRNA decay in humans at a glance. J Cell Sci 129, 461-467

9. Behm-Ansmant I, Gatfield D, Rehwinkel J, Hilgers V and 
Izaurralde E (2007) A conserved role for cytoplasmic poly(A)-binding protein 1 (PABPC1) in nonsense-mediated mRNA decay. EMBO J 26, 1591-1601

10. Eberle $A B$, Stalder L, Mathys $H$, Orozco RZ and Mühlemann O (2008) Posttranscriptional gene regulation by spatial rearrangement of the 3' untranslated region. PLoS Biol 6, e92

11. Ivanov PV, Gehring NH, Kunz JB, Hentze MW and Kulozik AE (2008) Interactions between UPF1, eRFs, PABP and the exon junction complex suggest an integrated model for mammalian NMD pathways. EMBO J 27, 736-747

12. Silva $A L$, Ribeiro $P$, Inácio $A$, Liebhaber $S A$ and Romão $L$ (2008) Proximity of the poly(A)-binding protein to a premature termination codon inhibits mammalian nonsense-mediated mRNA decay. RNA 14, 563-576

13. Metze S, Herzog VA, Ruepp MD and Mühlemann $O$ (2013) Comparison of EJC-enhanced and EJC-independent NMD in human cells reveals two partially redundant degradation pathways. RNA 19, 1432-1448

14. Conti E and Izaurralde E (2005) Nonsense-mediated mRNA decay: molecular insights and mechanistic variations across species. Curr Opin Cell Biol 17, 316-325

15. Fiorini F, Bagchi D, Le Hir H and Croquette V (2015) Human Upf1 is a highly processive RNA helicase and translocase with RNP remodelling activities. Nat Commun 6, 7581

16. Kashima I, Yamashita A, Izumi $\mathrm{N}$ et al (2006) Binding of a novel SMG-1-Upf1-eRF1-eRF3 complex (SURF) to the exon junction complex triggers Upf1 phosphorylation and nonsense-mediated mRNA decay. Genes Dev 20, 355-367

17. Melero R, Uchiyama A, Castaño R et al (2014) Structures of SMG1-UPFs complexes: SMG1 contributes to regulate UPF2-dependent activation of UPF1 in NMD. Structure 22, 1105-1119

18. Ohnishi T, Yamashita A, Kashima I et al (2003) Phosphorylation of hUPF1 induces formation of mRNA surveillance complexes containing hSMG-5 and hSMG-7. Mol Cell 12, 1187-1200

19. Okada-Katsuhata $Y$, Yamashita A, Kutsuzawa K, Izumi $\mathrm{N}$, Hirahara F and Ohno S (2012) N- and C-terminal Upf1 phosphorylations create binding platforms for SMG-6 and SMG-5:SMG-7 during NMD. Nucleic Acids Res 40, 1251-1266

20. Chang YF, Imam JS and Wilkinson MF (2007) The nonsense-mediated decay RNA surveillance pathway. Annu Rev Biochem 76, 51-74

21. Sun $X$ and Maquat LE (2000) mRNA surveillance in mammalian cells: the relationship between introns and translation termination. RNA 6, 1-8

22. Sun X, Moriarty PM and Maquat LE (2000) Nonsensemediated decay of glutathione peroxidase $1 \mathrm{mRNA}$ in the cytoplasm depends on intron position. EMBO J 19, 4734-4744

23. Zhang J, Sun X, Qian Y, Maquat LE et al (1998) Intron function in the nonsense-mediated decay of beta-globin mRNA: indications that pre-mRNA splicing in the nucleus can influence mRNA translation in the cytoplasm. RNA $4,801-815$
24. Le Hir H, Izaurralde E, Maquat LE and Moore MJ (2000) The spliceosome deposits multiple proteins 20-24 nucleotides upstream of mRNA exon-exon junctions. EMBO J $19,6860-6869$

25. L Le Hir H, Moore MJ and Maquat LE (2000) Pre-mRNA splicing alters mRNP composition: evidence for stable association of proteins at exon-exon junctions. Genes Dev 14, 1098-1108

26. Ishigaki Y, Li X, Serin G and Maquat LE (2001) Evidence for a pioneer round of mRNA translation: mRNAs subject to nonsense-mediated decay in mammalian cells are bound by CBP80 and CBP20. Cell 106, 607-617

27. Gregersen LH, Schueler M, Munschauer M et al (2014) MOV10 Is a 5' to 3' RNA helicase contributing to UPF1 mRNA target degradation by translocation along $3^{\prime}$ UTRs. Mol Cell 54, 573-585

28. Cho H, Kim KM and Kim YK (2009) Human proline-rich nuclear receptor coregulatory protein 2 mediates an interaction between mRNA surveillance machinery and decapping complex. Mol Cell 33, 75-86

29. Lejeune F, Li X and Maquat LE (2003) Nonsensemediated mRNA decay in mammalian cells involves decapping, deadenylating, and exonucleolytic activities. Mol Cell 12, 675-687

30. Huntzinger E, Kashima I, Fauser $M$, Saulière J and Izaurralde E (2008) SMG6 is the catalytic endonuclease that cleaves mRNAs containing nonsense codons in metazoan. RNA 14, 2609-2617

31. Mascarenhas R, Dougherty JA and Schoenberg DR (2013) SMG6 cleavage generates metastable decay intermediates from nonsense-containing beta-globin mRNA. PLoS One 8, e74791

32. Schmidt SA, Foley PL, Jeong DH et al (2015) Identification of SMG6 cleavage sites and a preferred RNA cleavage motif by global analysis of endogenous NMD targets in human cells. Nucleic Acids Res 43, 309-323

33. Chiu SY, Lejeune F, Ranganathan AC and Maquat LE (2004) The pioneer translation initiation complex is functionally distinct from but structurally overlaps with the steady-state translation initiation complex. Genes Dev 18, 745-754

34. Lejeune F, Ranganathan AC and Maquat LE (2004) elF4G is required for the pioneer round of translation in mammalian cells. Nat Struct Mol Biol 11, 992-1000

35. Belgrader P and Maquat LE (1994) Nonsense but not missense mutations can decrease the abundance of nuclear mRNA for the mouse major urinary protein, while both types of mutations can facilitate exon skipping. Mol Cell Biol 14, 6326-6336

36. Saulière J, Murigneux V, Wang Z et al (2012) CLIP-seq of elF4AIII reveals transcriptome-wide mapping of the human exon junction complex. Nat Struct Mol Biol 19, 1124-1131

37. Singh G, Kucukural A, Cenik C et al (2012) The cellular EJC interactome reveals higher-order mRNP structure and an EJC-SR protein nexus. Cell 151, 750-764

38. Wang J, Gudikote JP, Olivas OR and Wilkinson MF (2002) Boundary-independent polar nonsense-mediated decay. EMBO Rep 3, 274-279

39. Bühler $M$, Steiner $S$, Mohn F, Paillusson $A$ and 
Mühlemann O (2006) EJC-independent degradation of nonsense immunoglobulin-mu mRNA depends on 3' UTR length. Nat Struct Mol Biol 13, 462-464

40. Knezevic V, Ranson M and Mackem S (1995) The organizer-associated chick homeobox gene, Gnot1, is expressed before gastrulation and regulated synergistically by activin and retinoic acid. Dev Biol 171, 458-470

41. Nagy E and Maquat LE (1998) A rule for terminationcodon position within intron-containing genes: when nonsense affects RNA abundance. Trends Biochem Sci 23, 198-199

42. Kebaara BW and Atkin AL (2009) Long 3'-UTRs target wild-type mRNAs for nonsense-mediated mRNA decay in Saccharomyces cerevisiae. Nucleic Acids Res 37, 2771-2778

43. Graber JH, Cantor CR, Mohr SC and Smith TF (1999) Genomic detection of new yeast pre-mRNA 3'-endprocessing signals. Nucleic Acids Res 27, 888-894

44. Mignone F, Gissi C, Liuni S and Pesole G (2002) Untranslated regions of mRNAs. Genome Biol 3, REVIEWSO004

45. Singh G, Rebbapragada I and Lykke-Andersen J (2008) A competition between stimulators and antagonists of Upf complex recruitment governs human nonsense-mediated mRNA decay. PLoS Biol 6, e111

46. Toma KG, Rebbapragada I, Durand S and LykkeAndersen J (2015) Identification of elements in human long 3' UTRs that inhibit nonsense-mediated decay. RNA 21, 887-897

47. Durand S and Lykke-Andersen J (2013) Nonsensemediated mRNA decay occurs during elF4F-dependent translation in human cells. Nat Struct Mol Biol 20, 702-709

48. Rufener SC and Mühlemann O (2013) elF4E-bound mRNPs are substrates for nonsense-mediated mRNA decay in mammalian cells. Nat Struct Mol Biol 20, 710-717

49. Hogg JR and Goff SP (2010) Upf1 senses 3'UTR length to potentiate mRNA decay. Cell 143, 379-389

50. Kurosaki T, Li W, Hoque M et al (2014) A posttranslational regulatory switch on UPF1 controls targeted mRNA degradation. Genes Dev 28, 1900-1916

51. Kurosaki T and Maquat LE (2013) Rules that govern UPF1 binding to mRNA 3' UTRs. Proc Natl Acad Sci U S A 110, 3357-3362

52. Zünd $D$, Gruber AR, Zavolan $M$ and Mühlemann $O$ (2013) Translation-dependent displacement of UPF1 from coding sequences causes its enrichment in 3' UTRs. Nat Struct Mol Biol 20, 936-943

53. Thein SL, Winichagoon $P$, Hesketh $C$ et al (1990) The molecular basis of beta-thalassemia in Thailand: application to prenatal diagnosis. Am J Hum Genet 47, 369-375

54. Fang Y, Bateman JF, Mercer JF and Lamandé SR (2013) Nonsense-mediated mRNA decay of collagen-emerging complexity in RNA surveillance mechanisms. J Cell Sci $126,2551-2560$

55. Tan JT, Kremer F, Freddi $S$ et al (2008) Competency for nonsense-mediated reduction in collagen $X$ mRNA is specified by the 3' UTR and corresponds to the position of mutations in Schmid metaphyseal chondrodysplasia. Am J Hum Genet 82, 786-793

56. Cheng J, Belgrader P, Zhou X and Maquat LE (1994) Introns are cis effectors of the nonsense-codon-mediated reduction in nuclear mRNA abundance. Mol Cell Biol $14,6317-6325$

57. Zhang J, Sun X, Qian Y, LaDuca JP and Maquat LE (1998) At least one intron is required for the nonsensemediated decay of triosephosphate isomerase mRNA: a possible link between nuclear splicing and cytoplasmic translation. Mol Cell Biol 18, 5272-5283

58. Lejeune $\mathrm{F}$ and Maquat LE (2005) Mechanistic links between nonsense-mediated mRNA decay and premRNA splicing in mammalian cells. Curr Opin Cell Biol $17,309-315$

59. Li C, Lin RI, Lai MC, Ouyang P and Tarn WY (2003) Nuclear Pnn/DRS protein binds to spliced mRNPs and participates in mRNA processing and export via interaction with RNPS1. Mol Cell Biol 23, 7363-7376

60. Murachelli AG, Ebert J, Basquin C, Le Hir H and Conti E (2012) The structure of the ASAP core complex reveals the existence of a Pinin-containing PSAP complex. Nat Struct Mol Biol 19, 378-386

61. Tange TØ, Shibuya T, Jurica MS and Moore MJ (2005) Biochemical analysis of the EJC reveals two new factors and a stable tetrameric protein core. RNA 11, 18691883

62. Luo ML, Zhou Z, Magni K et al (2001) Pre-mRNA splicing and mRNA export linked by direct interactions between UAP56 and Aly. Nature 413, 644-647

63. Le Hir H, Gatfield D, Izaurralde E and Moore MJ (2001) The exon-exon junction complex provides a binding platform for factors involved in mRNA export and nonsense-mediated mRNA decay. EMBO J 20, 49874997

64. Degot S, Le Hir H, Alpy F et al (2004) Association of the breast cancer protein MLN51 with the exon junction complex via its speckle localizer and RNA binding module. J Biol Chem 279, 33702-33715

65. Andersen CB, Ballut L, Johansen JS et al (2006) Structure of the exon junction core complex with a trapped DEAD-box ATPase bound to RNA. Science 313, 19681972

66. Bono F, Ebert J, Unterholzner L, Güttler T, Izaurralde E and Conti E (2004) Molecular insights into the interaction of PYM with the Mago-Y14 core of the exon junction complex. EMBO Rep 5, 304-310

67. Jackson RJ, Hellen CU and Pestova TV (2010) The mechanism of eukaryotic translation initiation and principles of its regulation. Nat Rev Mol Cell Biol 11, 113-127

68. Gatfield D and Izaurralde E (2002) REF1/Aly and the additional exon junction complex proteins are dispensable for nuclear mRNA export. J Cell Biol 159, 579-588

69. Gatfield D, Le Hir H, Schmitt C et al (2001) The DExH/D box protein HEL/UAP56 is essential for mRNA nuclear export in Drosophila. Curr Biol 11, 1716-1721

70. Strässer K and Hurt E (2000) Yra1p, a conserved nuclear RNA-binding protein, interacts directly with Mex67p and is required for mRNA export. EMBO J 19, 410-420 
71. Lejeune F, Ishigaki Y, Li X and Maquat LE (2002) The exon junction complex is detected on CBP80-bound but not elF4E-bound mRNA in mammalian cells: dynamics of mRNP remodeling. EMBO J 21, 3536-3545

72. Green RE, Lewis BP, Hillman RT et al (2003) Widespread predicted nonsense-mediated mRNA decay of alternatively-spliced transcripts of human normal and disease genes. Bioinformatics 19, Suppl 1, i118-121

73. Lewis BP, Green RE and Brenner SE (2003) Evidence for the widespread coupling of alternative splicing and nonsense-mediated mRNA decay in humans. Proc Natl Acad Sci U S A 100, 189-192

74. Pan Q, Shai O, Lee LJ, Frey BJ and Blencowe BJ (2008) Deep surveying of alternative splicing complexity in the human transcriptome by high-throughput sequencing. Nat Genet 40, 1413-1415

75. Bourgeois CF, Lejeune F and Stévenin J (2004) Broad specificity of SR (serine/arginine) proteins in the regulation of alternative splicing of pre-messenger RNA. Prog Nucleic Acid Res Mol Biol 78, 37-88

76. Lareau LF, Brooks AN, Soergel DA, Meng Q and Brenner SE (2007) The coupling of alternative splicing and nonsense-mediated mRNA decay. Adv Exp Med Biol 623, 190-211

77. Lareau LF, Inada M, Green RE, Wengrod JC and Brenner SE (2007) Unproductive splicing of SR genes associated with highly conserved and ultraconserved DNA elements. Nature 446, 926-929

78. Bruno IG, Karam R, Huang $L$ et al (2011) Identification of a microRNA that activates gene expression by repressing nonsense-mediated RNA decay. Mol Cell 42, 500-510

79. Choe J, Cho H, Chi SG and Kim YK (2011) Ago2/ miRISC-mediated inhibition of CBP80/20-dependent translation and thereby abrogation of nonsense-mediated mRNA decay require the cap-associating activity of Ago2. FEBS Lett 585, 2682-2687

80. Choe J, Cho H, Lee HC and Kim YK (2010) microRNAV Argonaute 2 regulates nonsense-mediated messenger RNA decay. EMBO Rep 11, 380-386

81. Hosoda N, Kim YK, Lejeune F and Maquat LE (2005) CBP80 promotes interaction of Upf1 with Upf2 during nonsense-mediated mRNA decay in mammalian cells. Nat Struct Mol Biol 12, 893-901

82. Epstein JA, Lam P, Jepeal L, Maas RL and Shapiro DN (1995) Pax3 inhibits myogenic differentiation of cultured myoblast cells. J Biol Chem 270, 11719-11722

83. Gong C, Kim YK, Woeller CF, Tang Y and Maquat LE (2009) SMD and NMD are competitive pathways that contribute to myogenesis: effects on PAX3 and myogenin mRNAs. Genes Dev 23, 54-66

84. Choe J, Ahn SH and Kim YK (2014) The mRNP remodeling mediated by UPF1 promotes rapid degradation of replication-dependent histone mRNA. Nucleic Acids Res 42, 9334-9349

85. Azzalin CM and Lingner J (2006) The human RNA surveillance factor UPF1 is required for $S$ phase progression and genome stability. Curr Biol 16, 433-439

86. Belgrader P, Cheng J and Maquat LE (1993) Evidence to implicate translation by ribosomes in the mechanism by which nonsense codons reduce the nuclear level of human triosephosphate isomerase mRNA. Proc Natl Acad Sci U S A 90, 482-486

87. Maquat LE (2000) Nonsense-mediated RNA decay in mammalian cells: a splicing-dependent means to downregulate the levels of mRNAs that prematurely terminate translation. Translational Control of Gene Expression (edited by N. Sonenberg, J.B.W. Hershey, and M.B. Mathews) Cold Spring Harbor Laboratory Press: Cold Spring Harbor NY 849-868

88. Shoemaker CJ and Green R (2012) Translation drives mRNA quality control. Nat Struct Mol Biol 19, 594-601

89. Apcher S, Daskalogianni C, Lejeune F et al (2011) Major source of antigenic peptides for the MHC class I pathway is produced during the pioneer round of mRNA translation. Proc Natl Acad Sci U S A 108, 11572-11577

90. Kuroha K, Tatematsu T and Inada T (2009) Upf1 stimulates degradation of the product derived from aberrant messenger RNA containing a specific nonsense mutation by the proteasome. EMBO Rep 10, 1265-1271

91. Mazroui R, Di Marco S, Kaufman RJ and Gallouzi IE (2007) Inhibition of the ubiquitin-proteasome system induces stress granule formation. Mol Biol Cell 18, 2603-2618

92. Mocquet V, Neusiedler J, Rende F et al (2012) The human T-lymphotropic virus type 1 tax protein inhibits nonsense-mediated mRNA decay by interacting with INT6/EIF3E and UPF1. J Virol 86, 7530-7543

93. Morris C, Wittmann J, Jäck HM and Jalinot P (2007) Human INT6/elF3e is required for nonsense-mediated mRNA decay. EMBO Rep 8, 596-602

94. Martin L and Gardner LB (2015) Stress-induced inhibition of nonsense-mediated RNA decay regulates intracellular cystine transport and intracellular glutathione through regulation of the cystine/glutamate exchanger SLC7A11. Oncogene 34, 4211-4218

95. Wang D, Zavadil J, Martin L et al (2011) Inhibition of nonsense-mediated RNA decay by the tumor microenvironment promotes tumorigenesis. Mol Cell Biol 31, 3670-3680

96. Isken O, Kim YK, Hosoda N, Mayeur GL, Hershey JW and Maquat LE (2008) Upf1 phosphorylation triggers translational repression during nonsense-mediated mRNA decay. Cell 133, 314-327

97. Kunz JB, Neu-Yilik G, Hentze MW, Kulozik AE and Gehring NH (2006) Functions of hUpf3a and hUpf3b in nonsense-mediated mRNA decay and translation. RNA $12,1015-1022$

98. Nott A, Le Hir H and Moore MJ (2004) Splicing enhances translation in mammalian cells: an additional function of the exon junction complex. Genes Dev 18, 210-222

99. Keeling KM, Du M and Bedwell DM (2006) Therapies of Nonsense-Associated Diseases. Nonsense-mediated mRNA Decay - Landes Bioscience (Edited by Maquat LE) 121-136

100. Loughran G, Chou MY, Ivanov IP et al (2014) Evidence of efficient stop codon readthrough in four mammalian genes. Nucleic Acids Res 42, 8928-8938

101. Welch EM, Barton ER, Zhuo J et al (2007) PTC124 targets genetic disorders caused by nonsense mutations. 
Nature 447, 87-91

102. Du L, Damoiseaux R, Nahas S et al (2009) Nonaminoglycoside compounds induce readthrough of nonsense mutations. J Exp Med 206, 2285-2297

103. Salas-Marco J and Bedwell DM (2005) Discrimination between defects in elongation fidelity and termination efficiency provides mechanistic insights into translational readthrough. J Mol Biol 348, 801-815

104. Wang W, Czaplinski K, Rao Y and Peltz SW (2001) The role of Upf proteins in modulating the translation read-through of nonsense-containing transcripts. EMBO J 20, 880-890

105. Harger JW and Dinman JD (2004) Evidence against a direct role for the Upf proteins in frameshifting or nonsense codon readthrough. RNA 10, 1721-1729

106. Jia J, Werkmeister E, Gonzalez-Hilarion S et al, PTC-readthrough occurs in specific cytoplasmic foci and requires UPF proteins in human cells. [Under revision]

107. Keeling K.M, Xue X, Gunn G and Bedwell DM (2014) Therapeutics based on stop codon readthrough. Annu Rev Genomics Hum Genet 15, 371-394

108. Gonzalez-Hilarion S, Beghyn T, Jia J et al (2012) Rescue of nonsense mutations by amlexanox in human cells. Orphanet J Rare Dis 7, 58

109. Linde L, Boelz S, Nissim-Rafinia $M$ et al (2007) Nonsense-mediated mRNA decay affects nonsense transcript levels and governs response of cystic fibrosis patients to gentamicin. J Clin Invest 117, 683-692

110. Keeling KM, Wang D, Dai Y et al (2013) Attenuation of nonsense-mediated mRNA decay enhances in vivo nonsense suppression. PLoS One 8, e60478

111. Trcek T, Sato H, Singer RH and Maquat LE (2013) Temporal and spatial characterization of nonsensemediated mRNA decay. Genes Dev 27, 541-551

112. Durand S, Cougot N, Mahuteau-Betzer F et al (2007) Inhibition of nonsense-mediated mRNA decay (NMD) by a new chemical molecule reveals the dynamic of NMD factors in P-bodies. J Cell Biol 178, 1145-1160

113. Sheth $U$ and Parker R (2006) Targeting of aberrant mRNAs to cytoplasmic processing bodies. Cell 125, 1095-1109

114. Anderson P and Kedersha N (2009) RNA granules: post-transcriptional and epigenetic modulators of gene expression. Nat Rev Mol Cell Biol 10, 430-436

115. Zheng D, Chen CY and Shyu AB (2011) Unraveling regulation and new components of human P-bodies through a protein interaction framework and experimental validation. RNA 17, 1619-1634

116. Jia J, Furlan A, Gonzalez-Hilarion S et al (2015) Caspases shutdown nonsense-mediated mRNA decay during apoptosis. Cell Death Differ 22, 1754-1763

117. Popp MW and Maquat LE (2015) Attenuation of nonsense-mediated mRNA decay facilitates the response to chemotherapeutics. Nat Commun 6, 6632

118. Mendell JT, Sharifi NA, Meyers JL, Martinez-Murillo F and Dietz HC (2004) Nonsense surveillance regulates expression of diverse classes of mammalian transcripts and mutes genomic noise. Nat Genet 36, 1073-1078

119. Reggiori F and Klionsky DJ (2002) Autophagy in the eukaryotic cell. Eukaryot Cell 1, 11-21
120. Wengrod J, Martin L, Wang D, Frischmeyer-Guerrerio $P$, Dietz HC and Gardner LB (2013) Inhibition of nonsense-mediated RNA decay activates autophagy. Mol Cell Biol 33, 2128-2135

121. Li Z, Vuong JK, Zhang M, Stork C and Zheng S (2017) Inhibition of nonsense-mediated RNA decay by ER stress. RNA 23, 378-394

122. Karam $\mathrm{R}$, Lou $\mathrm{CH}$, Kroeger $\mathrm{H}$, Huang $\mathrm{L}$ and $\mathrm{Lin} \mathrm{JH}$ (2015) Wilkinson MF The unfolded protein response is shaped by the NMD pathway. EMBO Rep 16, 599-609

123. Oren YS, McClure ML, Rowe SM et al (2014) The unfolded protein response affects readthrough of premature termination codons. EMBO Mol Med 6, 685-701

124. Sieber J, Hauer C, Bhuvanagiri M et al (2016) Proteomic Analysis Reveals Branch-specific Regulation of the Unfolded Protein Response by Nonsense-mediated mRNA Decay. Mol Cell Proteomics 15, 1584-1597

125. Groenendyk J and Michalak M (2005) Endoplasmic reticulum quality control and apoptosis. Acta Biochim Pol 52, 381-395

126. Nickless A, Jackson E, Marasa J et al (2014) Intracellular calcium regulates nonsense-mediated mRNA decay. Nat Med 20, 961-966

127. Mcllwain DR, Pan Q, Reilly PT et al (2010) Smg1 is required for embryogenesis and regulates diverse genes via alternative splicing coupled to nonsense-mediated mRNA decay. Proc Natl Acad Sci U S A 107, 1218612191

128. Medghalchi SM, Frischmeyer PA, Mendell JT, Kelly AG, Lawler AM and Dietz HC (2001) Rent1, a trans-effector of nonsense-mediated mRNA decay, is essential for mammalian embryonic viability. Hum Mol Genet 10, 99-105

129. Thoren LA, Nørgaard GA, Weischenfeldt J et al (2010) UPF2 is a critical regulator of liver development, function and regeneration. PLoS One 5, e11650

130. Jolly LA, Homan CC, Jacob R, Barry S and Gecz J (2013) The UPF3B gene, implicated in intellectual disability, autism, ADHD and childhood onset schizophrenia regulates neural progenitor cell behaviour and neuronal outgrowth. Hum Mol Genet 22, 4673-4687

131. Nguyen LS, Jolly L, Shoubridge C et al (2012) Transcriptome profiling of UPF3B/NMD-deficient lymphoblastoid cells from patients with various forms of intellectual disability. Mol Psychiatry 17, 1103-1115

132. Tzschach A, Grasshoff U, Beck-Woedl S et al (2015) Next-generation sequencing in X-linked intellectual disability. Eur J Hum Genet 23, 1513-1518

133. Addington AM, Gauthier J, Piton A et al (2011) A novel frameshift mutation in UPF3B identified in brothers affected with childhood onset schizophrenia and autism spectrum disorders. Mol Psychiatry 16, 238-239

134. Laumonnier F, Shoubridge C, Antar C et al (2010) Mutations of the UPF3B gene, which encodes a protein widely expressed in neurons, are associated with nonspecific mental retardation with or without autism. Mol Psychiatry 15, 767-776

135. Tarpey PS, Raymond FL, Nguyen LS et al (2007) Mutations in UPF3B, a member of the nonsense- 
mediated mRNA decay complex, cause syndromic and nonsyndromic mental retardation. Nat Genet 39, 1127-1133

136. Nguyen LS, Kim HG, Rosenfeld JA et al (2013) Contribution of copy number variants involving nonsensemediated mRNA decay pathway genes to neurodevelopmental disorders. Hum Mol Genet 22, 18161825

137. Weischenfeldt J, Damgaard I, Bryder D et al (2008) NMD is essential for hematopoietic stem and progenitor cells and for eliminating by-products of programmed DNA rearrangements. Genes Dev 22, 1381-1396

138. Tinguely A, Chemin G, Péron S et al (2012) Cross talk between immunoglobulin heavy-chain transcription and RNA surveillance during B cell development. Mol Cell Biol 32, 107-117

139. Frischmeyer-Guerrerio PA, Montgomery RA, Warren DS et al (2011) Perturbation of thymocyte development in nonsense-mediated decay (NMD)-deficient mice. Proc Natl Acad Sci U S A 108, 10638-10643

140. Balistreri G, Horvath P, Schweingruber C et al (2014) The host nonsense-mediated mRNA decay pathway restricts Mammalian RNA virus replication. Cell Host Microbe 16, 403-411
141. Ajamian L, Abel K, Rao S et al (2015) HIV-1 Recruits UPF1 but Excludes UPF2 to Promote Nucleocytoplasmic Export of the Genomic RNA. Biomolecules 5, 2808-2839

142. Serquiña AK, Das SR, Popova E, Ojelabi OA, Roy CK and Göttlinger HG (2013) UPF1 is crucial for the infectivity of human immunodeficiency virus type 1 progeny virions. J Virol 87, 8853-8861

143. Viegas $\mathrm{MH}$, Gehring $\mathrm{NH}$, Breit $\mathrm{S}$, Hentze $\mathrm{MW}$ and Kulozik AE (2007) The abundance of RNPS1, a protein component of the exon junction complex, can determine the variability in efficiency of the Nonsense Mediated Decay pathway. Nucleic Acids Res 35, 4542-4551

144. Singh G, Jakob S, Kleedehn MG and Lykke-Andersen J (2007) Communication with the exon-junction complex and activation of nonsense-mediated decay by human Upf proteins occur in the cytoplasm. Mol Cell 27, 780-792

145. Kim VN, Kataoka N and Dreyfuss G (2001) Role of the nonsense-mediated decay factor hUpf3 in the splicingdependent exon-exon junction complex. Science 293, 1832-1836

146. Kuzmiak HA and Maquat LE (2006) Applying nonsensemediated mRNA decay research to the clinic: progress and challenges. Trends Mol Med 12, 306-316 